\title{
Detection of High Level Aminoglycosides Resistant Entrococci In A Tertiary Care Hospital.
}

\author{
Sivasankari S*., Somasunder V.M., Senthamarai S., Anitha C., Kumudhavathi \\ M.S., Suneel Kumar Reddy A., Amshavathani S.K., Venugopal . \\ Dept. of Microbiology, Meenakshi Medical College, Kanchipuram, Tamilnadu, India.
}

\begin{abstract}
:
BACKGROUND: Emergence of high-level aminoglycoside and glycopeptide resistance has significantly contributed to the mortality, particularly in serious enterococcal infections. High Level Aminoglycoside Resistance (HLAR) is related to the slow uptake or permeability of these agents. AIM: The present study was undertaken to determine HLAR pattern of enterococci in our hospital. METERIALS AND METHODS: This study was done in the Department of Microbiology, Meenakshi medical college, during the period of February 2012- February 2013. A total of 52 enterococcal isolates were collected from various clinical samples and speciation was by a series of biochemical reactions as per standard protocol.. Antibiotic susceptibility testing was done by Kirby Bauer disc diffusion method and microbroth dilution method according to CLSI guidelines 2012. RESULT: In the present study majority of the Enterococcal isolates in our study were isolated from urine sample. Among the 52 isolates of enterococci E.faecalis was the predominant species. The highest percentage of antibiotic resistance was seen in Erythromycin followed by Ciprofloxacin, Tetracycline, Ampicillin and Vancomycin. The High level Gentamycin Resistance (HLGR) was $48.7 \%$ in E.faecalis and $54.6 \%$ in E.faecium \& High Level Streptomycin Resistance (HLSR) was $34.1 \%$ in E.faecalis and $54.6 \%$ in E.faecium. 23 strains (17 E.faecalis and 6E.faecium) showed resistance to High Level Gentamycin (HLG) in the concentration range of $>500 \mu \mathrm{g} / \mathrm{ml}$. 17 strains (12E.faecalis and 5 E.faecium) showed resistance to High Level streptomycin (HLS) at the range of $>1000 \mu \mathrm{g} / \mathrm{ml}$. CONCLUSION: This study emphasizes the need to screen for HLAR in patients suffering from enterococcal infections. Routine screening for high level aminoglycoside resistance is important to limit the spread of resistance and to have a surveillance programme.
\end{abstract}

Keywords: HLAR, E.faecalis, E.faecium, Antibiotic susceptibility testing.

\author{
Abbreviation: \\ HLAR- High Level Aminoglycoside Resistance \\ HLGR- High level Gentamycin Resistance \\ HLSR- High Level Streptomycin Resistance \\ MIC - Minimum Inhibitory Concentration \\ CLSI- Clinical and Laboratory Standards Institute
}

\section{Introduction:}

Enterococci have now become the second most common cause of nosocomial infections. (Desai et al., 2001). The most common nosocomial infections caused by enterococci are Urinary tract infections, followed by intra abdominal and pelvic infections. E.faecalis $(80 \%$ to $90 \%)$ and E.faecium $(5 \%$ to $10 \%)$ are the most common species causing human infections. Enterococci have acquired resistance to several class of antibiotics either by mutation or through transfer of genetic material through plasmids and transposons (Murray et al., 1990).Along with Vancomycin resistance enterococci in addition to increasing incidence of HLAR is a major obstacle for treatment (Purva et al., 1999).

Enterococci have become increasingly important not only because of their ability to cause serious infections but also because of their increasing resistance to many antimicrobial agents. The emergence of high level resistance to aminoglycosides (HLAR), $\beta$ lactam antibiotics and to vancomycin by some strains, together with multi drug resistance has led to failure of synergistic effects of combination therapy.

It also exhibits a low to moderate level resistance to aminoglycosides, corresponding to minimum inhibitory concentration (MIC) of $62-500 \mu \mathrm{g} / \mathrm{ml}$. This resistance is related to the slow uptake or permeability of these agents. Aminoglycoside uptake is enhanced by exposing enterococci to a beta-lactam. HLAR (MIC > $2000 \mathrm{mg} / \mathrm{ml}$ ) has emerged recently, which is either ribosomally mediated or due to the production of inactivated enzymes (Sarika Jain et al., 2011). The limited choice of efficient therapy in serious enterococcal infections has been complicated by emergence of resistance to ampicillin, high-level aminoglycoside and glycopeptides.

The present study was undertaken for determining HLAR in enterococci, especially from our hospital 


\section{Meterials And Methods:}

This study was done in the Department of Microbiology Meenakshi medical college, during the period of February 2012- February 2013. A total of 52 enterococcal isolates were collected from various clinical samples (urine, pus, sputum, blood \& fluid) and identified by a series of biochemical reactions as per standard protocol according to CLSI guidelines 2012.

Antibiotic susceptibility testing done by Kirby Bauer disc diffusion method. The following antibiotic discs were used, Ampicillin $(10 \mu \mathrm{g}), \quad$ Erythromycin $(15 \mu \mathrm{g}), \quad$ Ciprofloxacin $(5 \mu \mathrm{g})$,Tetracycline $(30 \mu \mathrm{g})$,Vancomycin( $(30 \mu \mathrm{g})$. HLAR resistance was tested against Gentamicin $(120 \mu \mathrm{g})$ and Streptomycin $(300 \mu \mathrm{g})$.

The MIC was done by microbroth dilution for the following antibiotics: high level gentamicin, high level streptomycin (Ranbaxy pharma ltd.) by microbroth dilution method according to CLSI guidelines 2012. MIC was visually read after $24 \mathrm{hrs}$ of incubation at $37^{\circ} \mathrm{C}$. MIC was defined as the lowest drug concentration resulting in $90 \%$ reduction in turbidity when compared to the drug free control.The concentrations of the antibiotics ranged from 2000-1.95 $\mathrm{g}$ for HLG and HLS, Interpretive criteria for resistance to HLG and HLS according to CLSI guidelines 2012 were as follows: High level gentamicin $(>500)$ \&High level streptomycin $(>1000)$.

Statistical analysis:

Statistical analysis was done using SPSS software version 22.0. The test of proportions was used for analysing the resistance patterns between Kirby Bauer disc diffusion method and MIC by microbroth dilution method for different enterococcal species.

\section{RESULTS:}

3.1. SAMPLE DISTRIBUTION IN ENTEROCOCCAL ISOLATES

In the present study majority of the Enterococcal isolates in our study were isolated from Urine sample (55\%) followed by Pus (34.6\%), Blood (5.7\%) and Sputum (3.9\%). (TABLE-1)

TABLE-1 SHOWING SAMPLE DISTRIBUTION

SAMPLES
Urine
Pus
Sputum
Blood
Total

NO. OF SAMPLES
29
18
2
3
$\mathbf{5 2}$

PERCENTAGE
$55.8 \%$
$34.6 \%$
$3.9 \%$
$5.7 \%$
$\mathbf{1 0 0} \%$

\subsection{DISTRIBUTION OF AGE \&SEX IN ENTEROCOCCAL ISOLATES}

Highest prevalence was seen in female (65.4\%) followed by males (34.6\%). The maximum percentage of isolation was seen among the age group 40-60 years.

\subsection{DISTRIBUTION OF ENTEROCOCCAL SPECIES}

Among the 52 isolates of enterococci 41 isolates (78.8\%) were Efaecalis and 11 isolates $(21.2 \%)$ were E.faecium. (TABLE-2)

\section{TABLE-2 SHOWING SPECIES DISTRIBUTION}

$\begin{array}{ccc}\text { ENTEROCOCCUS SPECIES } & \text { NO.OF ISOLATES } & \text { PERCENTAGE } \\ \text { E.faecalis } & 41 & 78.8 \% \\ \text { E.faecium } & 11 & 21.2 \% \\ \text { Total } & \mathbf{5 2} & \mathbf{1 0 0} \%\end{array}$

\subsection{ANTIBIOTIC SUSCEPTIBILITY PATTERN OF ENTEROCOCCAL SPECIES}

Antibiotic Susceptibility Pattern of different species of Enterococcal Isolates By Kirby Bauer disc diffusion Method (Table 3)

TABLE-3 SHOWING ANTIBIOTIC SUSCEPTIBILITY PATTERN OF ENTEROCOCCAL ISOLATES BY KIRBY BAUER DISC DIFFUSION METHOD

\begin{tabular}{|c|c|c|c|c|c|c|c|c|}
\hline \multirow{3}{*}{ Antibiotic } & \multicolumn{4}{|c|}{ E.faecalis $(\mathrm{N}=\mathbf{4 1})$} & \multicolumn{4}{|c|}{ E.faecium $(\mathrm{N}=11)$} \\
\hline & \multicolumn{2}{|c|}{ Sensitive } & \multicolumn{2}{|c|}{ Resistant } & \multicolumn{2}{|c|}{ Sensitive } & \multicolumn{2}{|c|}{ Resistant } \\
\hline & No & $\%$ & No & $\%$ & No & $\%$ & No & $\%$ \\
\hline Erythromycin & 6 & 14.6 & 35 & 85.3 & 1 & 9.1 & 10 & 90.9 \\
\hline Ciprofloxacin $(5 \mu \mathrm{g})$ & 11 & 26.8 & 30 & 73.1 & 2 & 18.2 & 9 & 81.8 \\
\hline Tetracycline $(30 \mu \mathrm{g})$ & 11 & 26.8 & 30 & 73.1 & 6 & 54.6 & 5 & 45.4 \\
\hline Ampicillin $(10 \mu \mathrm{g})$ & 31 & 75.6 & 10 & 24.3 & 3 & 27.3 & 8 & 72.7 \\
\hline
\end{tabular}


Detection Of High Level Aminoglycosides Resistant Entrococci In A Tertiary Care Hospital.

$\begin{array}{ccccccccc}\text { High level gentamycin }(120 \mu \mathrm{g}) & 21 & 51.2 & 20 & 48.7 & 5 & 45.4 & 6 & 54.6 \\ \text { High level streptomycin }(300 \mu \mathrm{g}) & 27 & 65.8 & 14 & 34.1 & 5 & 45.4 & 6 & 54.6 \\ \text { Vancomycin }(30 \mu \mathrm{g}) & 37 & 90.2 & 4 & 9.3 & 9 & 81.8 & 2 & 18.2\end{array}$

Highest percentage of resistance to Erythromycin (85.3\% in E.faecalis and $90.9 \%$ in E.faecium) followed by Ciprofloxacin (73.1\% in E.faecalis and $81.8 \%$ in E.faecium), Tetracycline $(73.1 \%$ in E.faecalis and 45.4\% in E.faecium) and Ampicillin (24.3\% in E.faecalis and $72.7 \%$ in E.faecium).

Vancomycin resistance was $7.3 \%$ in E.faecalis and $18.2 \%$ in E.faecium.

The HLGR was $48.7 \%$ in E.faecalis and $54.6 \%$ in E.faecium \& HLSR was $34.1 \%$ in E.faecalis and $54.6 \%$ in E.faecium

\begin{tabular}{|c|c|c|c|c|c|c|}
\hline \multirow[b]{2}{*}{ Antibiotic drugs } & \multirow[b]{2}{*}{ Species } & \multicolumn{2}{|c|}{ MIC } & \multicolumn{3}{|c|}{ CLSI break points } \\
\hline & & Resistant isolates & Resistant \% & $\mathbf{S}$ & $\mathbf{I}$ & $\mathbf{R}$ \\
\hline \multirow{2}{*}{ High level gentamycin $(\mathrm{n}=26)$} & E.faecalis $(\mathrm{n}=20)$ & 17 & 41.5 & & & \\
\hline & E.faecium $(\mathrm{n}=6)$ & 6 & 54.5 & $\leq 500$ & - & $>500$ \\
\hline \multirow{2}{*}{$\begin{array}{l}\text { High level streptomycin } \\
\qquad(\mathrm{n}=20)\end{array}$} & E.faecalis $(\mathrm{n}=14)$ & 12 & 29.2 & & & \\
\hline & E.faecium $(\mathrm{n}=6)$ & 5 & 45.4 & $\leq 500$ & - & $>1000$ \\
\hline
\end{tabular}

23strains (17 E.faecalis and 6E.faecium ) showed resistance to HLG in the concentration range of $>500 \mu \mathrm{g} / \mathrm{ml}$. 17strains (12E.faecalis and 5E.faecium) showed resistance to HLS at the range of $>1000 \mu \mathrm{g} / \mathrm{ml}$.

3.6. Comparison of antibiotic resistance by Kirby Bauer disc diffusion method \&MIC of enterococcal species (Table 5)

\begin{tabular}{|c|c|c|c|c|}
\hline \multirow[b]{3}{*}{ Antibiotic } & \multicolumn{4}{|c|}{ DIFFUSION METHOD \&MIC } \\
\hline & \multicolumn{2}{|c|}{$\begin{array}{c}\text { E. faecalis }(\mathrm{N}=41) \\
\% \text { of Resistant isolates by }\end{array}$} & \multicolumn{2}{|c|}{$\begin{array}{c}\text { E.faecium }(\mathrm{N}=11) \\
\% \text { of Resistant isolates by }\end{array}$} \\
\hline & Disc diffusion method & MIC & Disc diffusion method & MIC \\
\hline High level gentamycin & 48.7 & 41.5 & 54.6 & 54.5 \\
\hline High level streptomycin & 34.1 & 29.2 & 54.6 & 45.4 \\
\hline
\end{tabular}

Comparison of antibiotic resistance by Kirby Bauer disc diffusion method \&MIC difference are not significant in our study and it was analysed statistically.

\section{Statistical analysis:}

The statistical analysis was taken up, to find if any difference in resistance level between Kirby Bauer disc diffusion method and MIC by microbroth dilution method. The differences are not significant. Hence the resistance levels by both the methods are same in our study.

\section{Discussion:}

In our present study, we have isolated $78.8 \%$ of E.faecalis and $21.2 \%$ of E.faecium. Only 2 species were recovered in contrast to more species by others from India (Desai et al., 2001, Bhat et al., 1997). Our isolation rate is close to Vinod Kumar et al 2011 who have isolated $81.03 \%$ of E. faecalis and $18.7 \%$ of E.faecium.

In this present study maximum number of enterococci were isolated from urine $(55.8 \%)$ followed by pus $(34.6 \%)$. This is slightly lower than Ruoff et al., 1990 who also isolated maximum number of enterococci from urine (68.2\%). Talebi et al 2007 also reported maximum number of enterococcal isolates from urine sample (85\%) followed by pus (15.5\%). Karmarkar et al., 2004 isolated $47.13 \%$ of enterococci from urine sample and described that urinary tract as commonest site of isolation of enterococci. The maximal enterococcal urine isolation could be due to structural abnormalities in the urinary tract, indwelling catheter or following any instrumentation.

Antibiotics resistance among Enterococci is a global problem. Antibiotic resistance in enterococci is either intrinsic or acquired. In our study the highest resistance is seen against Erythromycin $85.3 \%$ to E.faecalis and $90.9 \%$ to E.faecium, Sanal C. Fernandes et al., 2013,also have reported highest resistance to 
Erythromycin $81 \%$ to E.faecalis and $90.1 \%$ to E.faecium and also Sarika jain et al., 2011 also have reported a similar finding that highest resistance was seen in erythromycin $77.7 \%$ to E.faecalis and $89.6 \%$ to E.faecium.

In this study $24.3 \%$ of E. faecalis and $72.7 \%$ of E.faecium were resistant to ampicillin which was concordant with a study conducted by Salem-Bekhit et al., 2012, who also reported ampicillin resistance of $15.7 \%$ in E.faecalis and $70.4 \%$ in E.faecium.

In our study $73.1 \%$ of E.faecalis are resistant to ciprofloxacin and $81.8 \%$ of E.faecium are resistant to ciprofloxacin. Similar findings were also reported by Sarika Jain et al 2011 where $75 \%$ of E.faecalis and $84.4 \%$ of E.faecium were resistant to ciprofloxacin. In our study we have isolated $18.1 \%$ E.faecium and 9.3\% E.faecalis showing higher resistance of E.faecium. Similar findings were also reported by Karmarkar et al., 2004) who also reported greater resistance among E.faecium.

In our study $48.7 \%$ of E.faecalis and $54.6 \%$ of E. faecium were resistant to High level gentamycin. Similar findings were reported by Sanal C. Fernandes et al, $2013 \quad(53.5 \%$ of E.faecalis and $53 \%$ of E.faecium were resistant to High level gentamycin). The presence of HLGR is predictive of the loss of synergy between gentamicin and a cell-wall-active agent such as ampicillin or Vancomycin (Murray et al., 1998).

In our study $34.1 \%$ of E.faecalis and $54.6 \%$ of E.faecium were resistant to HLS. Similar findings were reported by Sanal C. Fernandes et al, 2013 who have reported $48.8 \%$ of E.faecalis and $58.8 \%$ of E.faecium were resistant to HLS.

In our study resistance to High level gentamycin was seen higher in Efaecium than in Effaecalis, similar findings were observed by Gordon et al 1992 who also reported significantly higher resistance to HLG and HLS by E.faecium than in E.faecalis. Similar result was also observed by Mendiratta et al.,2008. High HLGR in E.faecalis and HLSR in E.faecium observed has also been reported (Bhat et al., 1997, Agarwal et al.,1999) as also vice versa (Karmarkar et al., 2004). In our study HLG and HLS is slightly lower than other studies done all over India. The reason could be due to that our hospital is in a rural setup and usage of antibiotics is restricted. The reason for increased prevalence could be due to chronic cases.

All the enterococcal isolates resistant to HLG \& HLS by Kirby Bauer disc diffusion method were subjected to MIC by Micro broth dilution method. In our study MIC was in the range $>31.2-2000 \mu \mathrm{g} / \mathrm{ml}$ for HLG and MIC range of $>125-2000 \mu \mathrm{g} / \mathrm{ml}$ for HLS which was high compared to Ajay Kumar oli et al., 2012. In our study HLAR was high in E. faecium than in E.faecalis

\section{Conclusion:}

This study emphasizes the need to screen for HLAR in patients suffering from enterococcal infections as a routine screening for to detect HLGR and HLSR as this will help to limit the spread of resistance and have a surveillance pattern.

References

[1]. Agarwal VA, Jain YI, Pathak AA. Concomitant high level resistance to penicillin and aminoglycosides in enterococci at Nagpur, Central India. Indian J Med Microbiol 1999;17:85-7.

[2]. Ajay Kumar Oli, Rajeshwari H, Nagaveni S, and KelmaniChandrakanth R. Antimicrobial susceptibility pattern of enterococcus species isolated from clinical samples in south India Journal of Recent Advances in Applied Sciences. 2012;27:06-10,

[3]. Bhat KG, Chitra P, Bhat M. High level aminoglycoside resistance in Enterococci isolated from hospitalized patients. Indian J Med Res 1997;105:198-9.

[4]. Desai PJ ,Pandit D, Mathur M ,GogateA.Prevalence, identification and distribution of various species of enterococci isolated from clinical samples with special reference to urinary tract infection in catheterized patients. Indian J Med Microbial 2001;19:132-137.

[5]. Facklam RR, Carey RD, Ballows A, Hausler WJ, Shadomy HJ. The streptococci and aerococci.In Lennette EN.Manual of clinical Microbiology, 4th ed. American Society for Microbiol, Washington. D. C 1985. p. 154-7.

[6]. Jyothi Parameswarappa et al, Isolation, identification, and antibiogram of enterococci isolated from patients with urinary tract infection, Annals of African medicine.2013;12(3):176-181.

[7]. Karmarkar M.G. Enterococcal infections with special reference to phenotypic characterization \& drug resistance. Indian J Med Res Suppl May 2004;119:22-25.

[8]. Mendiratta DK et al,Status of high level aminoglycoside resistant E.faecalis and E.faecium in rural hospital in Central India”IJMM,(2008) 26(4):369-71.

[9]. Moellering RC Jr. Emergence of Enterococcus as a significant pathogen ClinInfec Dis 1992;14:1173-8.

[10]. Murray BE. Diversity among multidrug-resistant enterococci.Emerg Infect Dis 1998;4:37-47.

[11]. Murray BE. The life and times of the Enterococcus.ClinMicrobiol Rev 1990;3:46-65.

[12]. Purva M, Rama C, Benu D, Nidhi S and Lalit K. Vancomycin resistant Enterococcal bacteremia in a lymphoma patient. Indian J Med Microbiol 1999;17(4): 194-195.

[13]. Ruoff LK, Spargo DJ, Ferraro JM "Species identification of Enterococci Isolates from Clinical Specimens" J ClinMicrobiol 1990;28:435-437.

[14]. Salem-BekhitMM et al., Prevalence and antimicrobial resistance pattern of multidrug-resistant enterococci isolated from clinical specimens.Indian Journal of Medical Microbiology.2012;30(1):44-5.

[15]. Sanal C. Fernandes et al, "Drug resistance \& virulence determinants in clinical isolates of Enterococcus species, IJMR, May2013;137:981-985.

[16]. Sarika Jain et al,Clinicoepidiomological profile and high level aminoglycoside resistance in enterococcal septicaemia from a tertiary care hospital in east Delhi. International J of Basic Medical Research. Jul-Dec 2011; Vol 1(2):354-360. 
[17]. Seema Bose et al, Prevalence Of Drug Resistance Among Enterococcus Spp Isolated From A Tertiary Care Hospital,Int J Med Health Sci. July 2012,Vol-1;Issue-3.

[18]. Stevenson KB, Murray EW, Sarubbi FA. Enterococcal meningitis: Report of four cases and Review. J Clin Infect Dis 1994; $18: 233$ 239.

[19]. Talebi M. Characterization of Vancomycin Resistant Enterococcus faecium" Iranian JPubl Health. 2007;36(4):20-25

[20]. Vinodkumar C.Isolation of bacterio3.phages to multi-drug resistant Enterococci obtained from diabetic foot: A novel antimicrobial agent waiting in the shelf? Indian Journal of Pathology and Microbiology.2011.54(1);90:657-662. 